\title{
PROMESSAS E RESULTADOS DA NOVA GESTÃO PÚBLICA NO BRASIL: 0 CASO DAS ORGANIZAÇÕES SOCIAIS DE SAÚDE EM SÃO PAULO
}

THE PROMISES AND RESULTS OF NEW PUBLIC MANAGEMENT IN BRAZIL: THE CASE OF SOCIAL HEALTH ORGANIZATIONS IN SÃO PAULO

\section{RESUMO}

O modelo da Nova Gestão Pública (NGP) espalhou-se pelo mundo com a promessa de atacar dois males burocráticos: o excesso de procedimentos e a baixa responsabilização dos burocratas frente ao sistema político e à sociedade. A proposta básica foi flexibilizar a administração pública e aumentar a accountability com uma nova forma de provisão dos serviços, baseada na criação de entidades públicas não estatais como as organizações sociais (OS). No Brasil, a experiência reformista se inicia em 1995 com as idéias do Plano Diretor da Reforma do Aparelho do Estado. No campo da saúde, o caso de São Paulo constitui um caso paradigmático para avaliar a implantação da NGP no Brasil. A promessa de maior accountability avançou, mas ainda não alterou o insulamento do Poder Executivo e a baixa capacidade de controle institucional e social sobre ele.

\section{Hironobu Sano}

Pesquisador do Instituto de Defesa do Consumidor

hiro.sano@gmail.com

\section{Fernando Luiz Abrucio}

Professor do Programa de Pós-Graduação em Administração Pública e Governo da Escola de Administração de Empresas de São Paulo, Fundação Getulio Vargas

fernando.abrucio@fgv.br

Recebido em 29.06.2006. Aprovado em 14.04.2008

Avaliado pelo sistema double blind review

Editor Científico: Organizadores do Fórum de Organizações Sociais

\begin{abstract}
The new public management (NPM) model has spread through the world with its promise of attacking two bureaucratic evils: an excessive number of procedures and the low accountability of bureaucrats vis-à-vis the political system and society. NPM's basic proposal was to make public administration more flexible and increase its accountability through a new way of providing services that is based on the creation of public non-governmental entities like social organizations (SO). In Brazil, reformist experience begins in 1995 started with the ideas of the Master Plan for Reforming the Public Administration. In the Health field, the experience in Sao Paulo constitutes a paradigmatic case study for evaluating the introduction of NPM in Brazil. The promise of greater accountability has advanced, but has not yet changed the insulating of the Executive Branch and the reduced capacity of institutional and society for controlling it.
\end{abstract}

PALAVRAS-ChAVE Nova Gestão Pública, organizações sociais, reforma do Estado, flexibilização administrativa, accountability, controles horizontais e sociais.

KEYWORDS New public management, social organizations, reform of State, administrative flexibilization, accountability, horizontal and social controls, state political system. 


\section{INTRODUÇÃO}

Idéias e reformas ancoradas na chamada Nova Gestão Pública (NGP) proliferaram nos últimos 20 anos, alimentando processos de mudança em diversos países (POLLITT e BOUCKAERT, 2002), a fim de atacar dois males burocráticos: a ineficiência relacionada ao excesso de procedimentos e controles processuais, e a baixa responsabilização dos burocratas frente ao sistema político e à sociedade. Para alcançar esses objetivos, sua proposta básica foi flexibilizar a administração pública e aumentar a accountability ou responsabilização governamental (CLAD, 2000).

$\mathrm{O}$ Brasil não ficou de fora dessa onda reformista. $\mathrm{O}$ Plano Diretor da Reforma do Aparelho do Estado, formulado pelo então Ministério da Administração Federal e Reforma do Estado (Mare), seguiu muitas das linhas básicas da Nova Gestão Pública. Além disso, vários governos estaduais adotaram posteriormente essas novas formas de gestão. Este artigo analisa uma das experiências brasileiras que tentou seguir o paradigma da NGP: a experiência das organizações sociais (OS) em São Paulo no campo da Saúde, em que houve o repasse de equipamentos sociais a entidades da sociedade civil.

As primeiras organizações sociais foram criadas pelo governo federal em 1997. O estado de São Paulo foi o ente federativo em que essa forma de gestão mais proliferou. Em pouco tempo, foram qualificadas nove entidades como OS na área da Saúde, responsáveis pelo gerenciamento de 16 hospitais - além dessas, outras nove organizações tiveram o mesmo destino na área da Cultura.

Já há alguns estudos sobre OS brasileiras, inclusive análises sobre a experiência paulista na transferência da gestão de hospitais para entidades da sociedade civil. Porém, tais trabalhos concentraram-se na questão da melhoria do desempenho na provisão dos serviços. Não houve até agora uma pesquisa que buscasse entender as OS pelo prisma da accountability. É essa lacuna que o presente artigo pretende preencher. O problema de pesquisa que orienta este trabalho é saber se a experiência dos hospitais de São Paulo geridos por organizações sociais, uma das maiores novidades brasileiras no campo da gestão pública, incorporou plenamente os princípios da NGP: flexibilização administrativa com aumento da accountability.

Para analisar a experiência das organizações sociais da saúde em São Paulo e sua capacidade em combinar as características-chave da NGP, três opções teóricometodológicas foram adotadas. Primeiro, a base do artigo é uma pesquisa histórica pela via de documentos, estruturas legais e entrevistas. Procurou-se, desse modo, ver quais eram as opções em jogo e quem teve maior poder de influência. O suposto causal da pesquisa é de que as regras e instituições que regem os contratos são importantes, mas não explicam completamente o funcionamento das OS, particularmente em termos de accountability.

O desenho contratual é fundamental para entender a dinâmica das OS, mas é preciso entender as razões que levaram à escolha de tais instituições, bem como os argumentos contrários a elas. Por isso, foram feitas 32 entrevistas abertas, com atores vinculados ao governo federal, ao Executivo estadual, à Assembléia Legislativa e ao TCE de São Paulo, com membros do Conselho Estadual de Saúde, além de terem sido ouvidos acadêmicos e especialistas em gestão hospitalar. As entrevistas foram realizadas entre 2002 e 2007, o que permite dimensionar os propósitos iniciais vis-à-vis aos resultados efetivos, analisando o conteúdo estrito das respostas e seu sentido para os agentes envolvidos.

Por fim, para a construção da hipótese de trabalho, adotou-se como referencial teórico a literatura neo-institucionalista, que investiga o peso do Poder Executivo brasileiro na produção e no controle das políticas públicas. Em particular, foi usado o conjunto de trabalhos que realçam o caráter ultrapresidencialista (ABRUCIO, 1998) dos estados brasileiros como uma variável-chave para explicar o arcabouço organizacional adotado pelas OS paulistas, com seus respectivos resultados para a accountability.

O artigo conta, além desta Introdução, com três seções mais a conclusão. A primeira seção, dividida em três etapas, contextualiza o objeto da pesquisa. Inicialmente, resume a proposta de mudança do modelo de provisão de serviços públicos segundo a Nova Gestão Pública. Em seguida, discute brevemente a reforma do Estado no Brasil recente. Por fim, apresenta a teoria da accountability governamental e seu lugar na NGP.

Na segunda seção do texto, mapeiam-se as OS do país, analisando-se seu desenho institucional e comparando-se a accountability dos modelos subnacionais. Mais adiante, são analisadas as OS paulistas na área da Saúde.

A parte mais substantiva do texto trata da accountability dessas OS. Para tanto, primeiro faz-se um estudo da gênese desse processo. Depois, analisa-se o funcionamento efetivo dos instrumentos de controle, a fim de se investigarem as condições atuais de responsabilização das OS de saúde em São Paulo. Na Conclusão, procurase avaliar os avanços e limites dessa experiência reformista brasileira em relação às idéias preconizadas pelo modelo da NGP. 


\section{A NOVA GESTÃO PÚBLICA E 0 PLANO DIRETOR DA REFORMA DO APARELHO DO ESTADO: A ADAPTAÇÃO PARA O CASO BRASILEIRO}

É possível resumir a preocupação central da Nova Gestão Pública como a combinação entre a flexibilização da gestão e o aumento da responsabilização da administração pública. A implementação dessa proposta, contudo, depende da peculiaridade dos países, principalmente no que se refere ao legado estatal e à dinâmica política, como realçam os principais estudos comparativos (ver, por exemplo, FLYNN \& STREHL, 1996; e POLLITT \& BOUCKAERT, 2000). A singularidade do caso brasileiro, e mais especificamente da experiência paulista, realçam esse aspecto.

Para concretizar os objetivos da NGP, três mecanismos são essenciais:

a) A adoção de uma administração pública voltada para resultados, baseada em mecanismos de contratualidade da gestão, com metas, indicadores e formas de cobrar os gestores, e apoiada na transparência das ações governamentais, possibilitando o controle maior dos cidadãos e o uso de outros instrumentos de accountability.

b) A contratualidade supõe, ademais, a existência de uma pluralidade de provedores de serviços públicos - aquilo que Bradach e Eccles (1989) chamam, de um modo plural, de governança (plural mode of governance). Desse modo, é possível estabelecer formas contratuais de gestão em estruturas estatais e entes públicos não estatais.

c) Por fim, a combinação entre a flexibilização da gestão burocrática e o aumento da responsabilização da administração pública será mais bem-sucedida caso funcionem adequadamente os mecanismos institucionais de controle (CLAD, 2000). Como veremos adiante, esse é $\mathrm{o}$ aspecto mais intrincado no caso brasileiro.

As idéias da NGP chegaram ao Brasil no primeiro governo Fernando Henrique Cardoso, em 1995, quando foi criado o Ministério da Administração e Reforma do Estado (Mare), sob o comando do ministro Bresser-Pereira, e proposto o Plano Diretor da Reforma do Aparelho do Estado, que apresentou um diagnóstico da administração pública federal, pautado, em boa medida, pelas idéias da NGP.

Segundo a visão do ministro Bresser-Pereira, o sistema administrativo brasileiro, nascido da Constituição de 1988, tinha realçado os piores elementos do modelo burocrático, com o reforço da lógica dos procedimentos, a uniformização e o "engessamento" da estrutura dos órgãos públicos e da política de pessoal, somados ao baixo controle público da burocracia. Para mudar essa situação seria necessário, de um lado, flexibilizar a gestão pública e, de outro, tornar o corpo burocrático mais accountable em relação aos cidadãos.

O Plano Diretor era o instrumento aglutinador dessa proposta. Ao contrário do que diziam os críticos da época, sua concepção não defendia o Estado mínimo e tampouco propunha a destruição da "burocracia weberiana", definida como a estrutura profissional e meritocrática que deve prevalecer no funcionalismo. Além do caráter extremamente ideologizado do debate daquela época, essa confusão foi causada pela defesa da então chamada administração pública gerencial como uma nova etapa na história do aparelho estatal. É possível afirmar que o projeto do ministro Bresser-Pereira teve como principal legado

... a continuação e aperfeiçoamento da civil service reform, por mais que o discurso do Plano Diretor da Reforma do Estado se baseasse numa visão (erroneamente) etapista - com a reforma gerencial vindo depois da burocrática. Houve uma grande reorganização administrativa do Governo Federal, com destaque para a melhoria substancial das informações da administração pública - antes desorganizadas ou inexistentes - e o fortalecimento das carreiras de Estado. Um número importante de concursos foi realizado e a capacitação feita pela Enap, revitalizada. Em suma, o ideal meritocrático contido no chamado modelo weberiano não foi abandonado pelo Mare; ao contrário, foi aperfeiçoado. (ABRUCIO, 2007, p. 71).

No plano proposto pelo Mare, o principal ponto de convergência com a NGP estava no desenho institucional. Nessa concepção, o Estado atuaria mais como regulador e promotor dos serviços públicos e buscaria, preferencialmente, a "descentralização, a desburocratização e o aumento da autonomia de gestão" (BRESSER-PEREIRA, 1998, p. 206). Para alcançar esse objetivo, o aparelho estatal deveria fortalecer o corpo burocrático ao mesmo tempo em que se criaria um modelo de gestão orientado por resultados e baseado na contratualização, seja com os órgãos internos ao aparelho estatal, seja com entes públicos não estatais, por meio daquilo que foi chamado de organizações sociais (OS).

A despeito do caráter inovador dessas idéias, sua implementação foi marcada por uma série de vicissitudes. Em primeiro lugar, o Plano Diretor sofreu uma forte reação congressual e do funcionalismo, além de ter tido um apoio social difuso - ao contrário da Lei de Responsabilidade Fiscal, que recebeu forte impulso da opinião pública. O legado patrimonialista do Estado brasileiro e os efeitos 
perversos das primeiras propostas de reforma do Estado feitas pelo presidente Collor geraram uma enorme desconfiança. Além disso, o próprio governo FHC não apoiava integralmente esse projeto, pois sua preocupação maior era com o ajuste fiscal. Na visão da equipe econômica, núcleo hegemônico na estrutura de poder, a flexibilização da gestão pública e a delegação de funções que continuariam a ser financiadas pelo Estado poderiam prejudicar as metas fiscalistas. Assim, segundo Flávio Rezende, criouse entre os principais atores governamentais uma tensão entre o controle das contas públicas e o modelo gerencial (REZENDE, 2004).

Tais reações afetaram as medidas mais inovadoras de redesenho da administração pública propostas pelo Plano Diretor. As agências executivas nunca saíram do papel, e as organizações sociais nasceram fragilizadas, sendo implementadas numa ínfima parcela do governo federal. No entanto, graças ao trabalho disseminador do ministro Bresser-Pereira e à iniciativa de alguns governos estaduais, as OS foram mais bem-sucedidas no plano subnacional. Elas se espalharam pelo país, inclusive em governos de matiz partidário diferente do dominante no plano nacional (ABRUCIO e GAETANI, 2006), gerando a flexibilização das organizações e a melhora do desempenho administrativo, como veremos no caso dos hospitais públicos paulistas. No entanto, o sistema de controles públicos teve pouca efetividade sobre o modelo das OS.

\section{A accountability e suas dimensões}

A importância que o Plano Diretor confere ao tema do controle reflete o destaque que a discussão em torno da utilização do termo "accountability" ganhou tanto no Brasil como na América Latina (CAMPOS, 1990; CUNILL GRAU, 2000; CLAD, 2000). Na sua acepção original, "accountability" diz respeito "al cumplimiento de una obligación del funcionario público de rendir cuentas, sea a un organismo de control, al parlamento o a la sociedad misma" (CLAD, 2000, p. 329). Essa obrigatoriedade é inerente à palavra, e todo agente público deve estar ciente dessa obrigação - trata-se de um valor metapolítico. Por isso, a análise da accountability envolve o estudo dos diferentes mecanismos institucionais de responsabilização, divididos em duas vertentes. A primeira é a dimensão vertical da accountability, que tem nas eleições seu principal instrumento e traz para a cena o mecanismo tradicional de premiação e castigo. A outra dimensão da accountability corresponde aos mecanismos horizontais, ou o "velho tema da divisão dos poderes e dos controles e equilíbrios entre eles" (O'DONNELL, 1998, p. 38). O desenvolvimento da democracia também trouxe novas instituições que complementam o controle mútuo exercido entre os Poderes Executivo, Legislativo e Judiciário, como o controle por resultados e por mecanismos de participação social.

Partindo de um estudo do Conselho Científico do Clad (2000), os mecanismos de responsabilização podem ser divididos em quatro grupos: responsabilização pelo controle parlamentar; responsabilização pelo controle de procedimentos; responsabilização pelo controle social; e responsabilização pelo controle de resultados. Cada um desses mecanismos está relacionado com os responsáveis pelo controle, conforme verificamos no Quadro 1.

A responsabilização pelo controle parlamentar consiste fundamentalmente no controle mútuo entre os Poderes Executivo e Legislativo. Novamente tomando como base o trabalho do Clad (2000), existem quatro mecanismos principais de controle parlamentar: (1) a submissão das nomeações realizadas pelo Executivo a importantes cargos públicos à aprovação do Legislativo, como a da presidência do Banco Central; (2) o controle na elaboração e gestão do orçamento, e também da prestação de contas do Poder Executivo; (3) a existência e o funcionamento pleno das comissões parlamentares destinadas a avaliar as políticas públicas e a investigar a transparência dos atos governamentais; e (4) as audiências públicas utilizadas para a discussão, na sociedade, de projetos de leis e programas antes de sua implementação.

\section{Quadro 1 - Tipo de controle x controlador}

\begin{tabular}{|c|c|c|c|c|}
\hline \multirow[b]{2}{*}{ CONTROLADORES } & \multicolumn{4}{|c|}{ TIPO DE RESPONSABILIZAÇÃO } \\
\hline & $\begin{array}{c}\text { CONTROLE } \\
\text { PARLAMENTAR }\end{array}$ & $\begin{array}{c}\text { CONTROLE DE } \\
\text { PROCEDIMENTOS }\end{array}$ & CONTROLE SOCIAL & $\begin{array}{l}\text { CONTROLE DE } \\
\text { RESULTADOS }\end{array}$ \\
\hline Políticos & $x$ & & & $X$ \\
\hline Burocratas & & $x$ & & $X$ \\
\hline Sociedade & & & $X$ & $x$ \\
\hline
\end{tabular}

Fonte: Adaptado de CLAD, 2000, p.39. 
O controle de procedimentos administrativos, por sua vez, corresponde àquele exercido pelos burocratas e tem como objetivo fazer com que as normas e os procedimentos legais sejam cumpridos, exercidos por organizações como os Tribunais de Contas, que realizam a auditoria formal das ações governamentais.

O principal problema das eleições é que os eleitores opinam apenas no momento da votação. Hoje, contudo, já existem outros espaços públicos que demandam a participação da sociedade ao longo do mandato, como, por exemplo, as audiências públicas e os conselhos gestores de políticas públicas.

Por fim, a introdução da lógica de resultados muda o enfoque das políticas públicas dos procedimentos para os resultados, promovendo a flexibilidade na gestão das atividades e oferecendo um novo conjunto de informações para os cidadãos controlarem os governantes.

Todos esses mecanismos de responsabilização são essenciais para a NGP, uma vez que a mudança no padrão de gestão não se dá apenas no plano interno em prol da maior eficiência gerencial, mas também passa pela construção de uma administração voltada aos cidadãos. No estudo das OS, procuraremos entender se na experiência paulista houve ou não articulação entre a dimensão mais gerencial e a de accountability.

\section{AS ORGANIZAÇÕES SOCIAIS: DEFINIÇÃO, TRAJETÓRIA E O PAPEL DA ACCOUNTABILITY}

O modelo das organizações sociais foi criado tendo como base a combinação entre a flexibilização da gestão pública e o aumento da accountability governamental. Por meio de um contrato de gestão, o Estado repassaria a entes públicos não estatais a provisão de serviços não exclusivos, entidades estas qualificadas como OS. Caberia à máquina estatal a regulação e o financiamento básico desse processo. As OS perseguiriam dois objetivos: (1) garantir autonomia, flexibilidade e maior responsabilidade para os dirigentes desses serviços; e (2) levar ao incremento do controle social dessas entidades, fortalecendo práticas que aumentem a participação da sociedade na formulação e na avaliação do desempenho da OS, ampliando a parceria entre o Estado e a sociedade (BRASIL, 1997, p. 11).

No âmbito federal, as OS foram criadas por meio da Medida Provisória $n^{\circ}$ 1.591, de 9 de outubro de 1997, que posteriormente foi regulamentada na forma da Lei $\mathrm{n}^{\circ}$ 9.637, de 15 de maio de 1998. A partir desse modelo, muitos outros estados da Federação também implantaram versões locais de OS. No final de 2007 , havia 70 organizações qualificadas em âmbito subnacional, distribuídas por todas as regiões do país, concentrando-se no Sudeste e Nordeste, conforme dados que a Tabela 1 discrimina por estado e área de atuação.

A análise da tabela mostra que as entidades concentram-se nas três primeiras áreas de atuação - Saúde, Cultura e Ciência e Tecnologia -, com predominância do setor da Saúde, por conta do modelo adotado numa parte extensa da rede estadual paulista. Essa experiência pioneira serviu de inspiração para os demais governos, com um total de 24 OS no campo da Saúde em todo o território nacional. O estado de São Paulo também se sobressai por ser o governo que mais qualificou OS.

O contrato de gestão é amplamente utilizado na administração pública, e diversos estudos (ANDRÉ, 1994, 1995 e 1999; ROBLES e FISCHMANN, 1995) apresentam suas possibilidades e limites. André (1999), por exemplo, define o contrato de gestão como o instrumento legal de "compromisso administrativo interno ao Estado, firmado entre o Poder Executivo e a diretoria de instituições de direito público e empresas estatais".

Em relação ao modelo tradicional de contratualização, as OS teriam duas peculiaridades em sua concepção original: seriam instituições de direito privado, habilitadas a celebrar contratos de gestão com o Estado, e, em tese, deveriam ampliar os mecanismos de transparência e accountability.

\section{Mecanismos de accountability das organizações sociais}

Para possibilitar o acompanhamento das atribuições, responsabilidades e obrigações das OS, a legislação federal estabeleceu os seguintes instrumentos:

1. programa de trabalho da OS;

2. metas e prazos de execução;

3. critérios objetivos de avaliação de desempenho que utilizem indicadores de qualidade e produtividade;

4. limites para despesas com remuneração dos dirigentes e empregados.

Uma vez estabelecidos os parâmetros, o controle sobre as OS ocorre a partir do acompanhamento e da avaliação dos resultados obtidos pela entidade, que são comparados com o que foi previamente acordado no contrato de gestão, o que configura a "responsabilização pelo controle de resultados". Isso é feito pela Comissão de Avaliação, sob a responsabilidade do "órgão ou entidade supervisora da área de atuação correspondente à atividade fomentada" (BRASIL, Lei $n^{\circ}$ 9.637/98). Os relatórios conclusivos são 
enviados ao órgão supervisor, cujos membros devem ser indicados pela autoridade supervisora. O Quadro 2 apresenta as instâncias de controle previstas na legislação.

A dimensão vertical ocorre quando existe relação hierárquica entre as partes envolvidas. Nesse caso, o órgão supervisor representa o governo, enquanto a organização social representa um ente criado sob a tutela do Estado. O Tribunal de Contas, órgão auxiliar do Legislativo, seria o responsável pela auditoria nas contas e nos procedimentos administrativos das OS, emitindo pareceres sobre sua atuação.

Seguindo a classificação dos tipos de responsabilização, o controle social ocorreria a partir do momento em que o conselho de administração da OS acompanhasse o desenvolvimento das atividades da própria entidade, procurando garantir o respeito ao contrato de gestão. A lei define que o "controle social" deve ser uma diretriz seguida, porém não especifica como isso deve ocorrer para que haja um processo transparente contínuo. Algumas medidas presentes na legislação federal permitem identificar certos mecanismos que promovem a transparência. O Quadro 3 apresenta uma lista de relatórios e a obrigatoriedade de sua publicação.

O quadro indica que a obrigatoriedade de publicação da íntegra do contrato de gestão está prevista apenas nas legislações de Curitiba, Bahia e São Paulo, o que revela

Tabela 1 - Número de organizações sociais qualificadas por UF e área de atuação

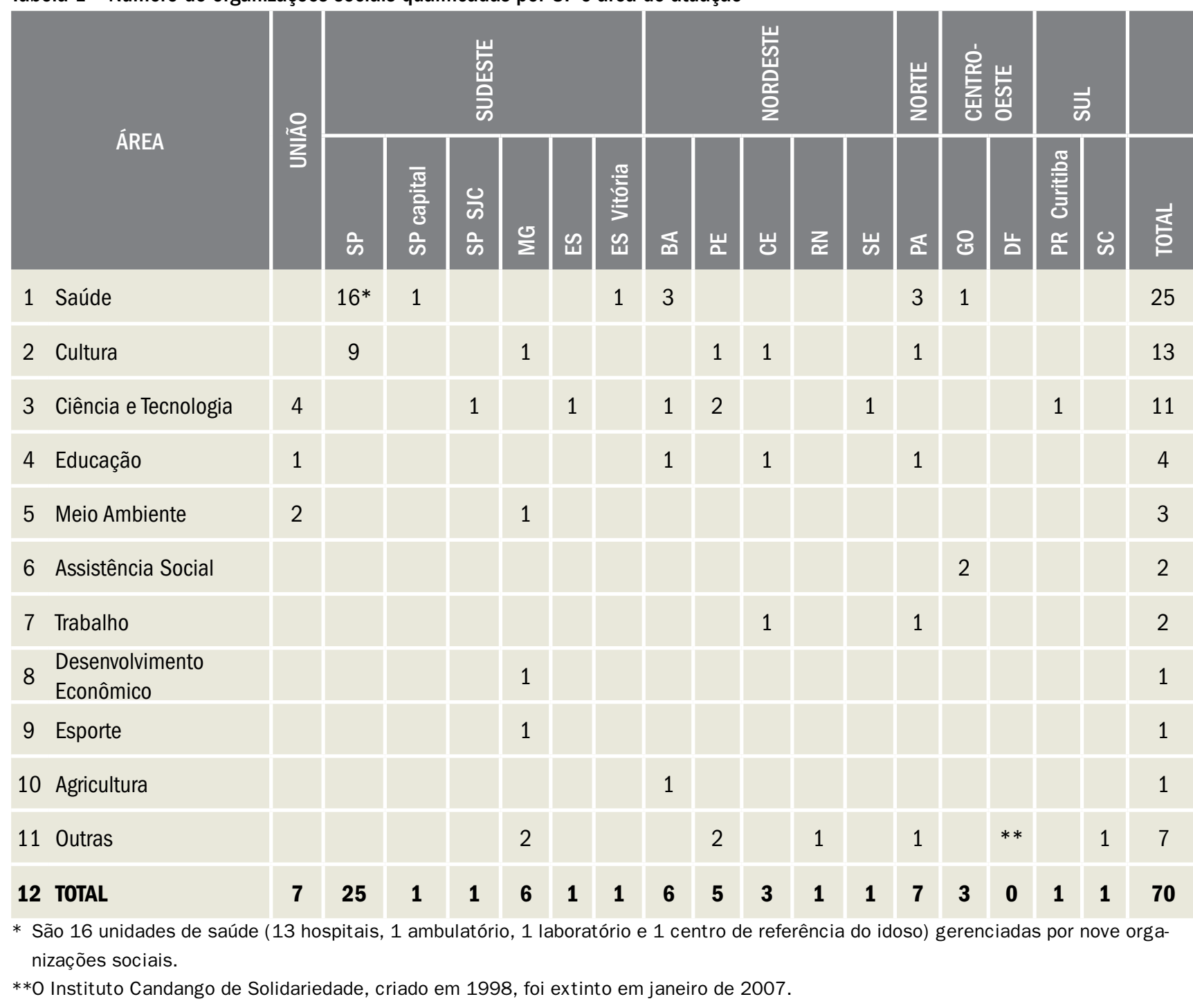


Quadro 2 - Desenho institucional das organizações sociais

\begin{tabular}{|c|l|l|l|}
\hline$\#$ & \multicolumn{1}{|c|}{ CONTROLADOR } & \multicolumn{1}{c}{ RESPONSABILIZAÇÃO } & DIMENSÃO \\
\hline 1. & Órgão Supervisor & Controle de Resultados & Vertical \\
\hline 2. & Comissão de Avaliação & Controle de Resultados & Horizontal \\
\hline 3. & Tribunal de Contas & Controle de Procedimentos & Vertical e Horizontal \\
\hline 4. & Conselho de Administração & Controle Social & \\
\hline
\end{tabular}

Quadro 3 - Publicação dos documentos do contrato de gestão

\begin{tabular}{|c|c|c|c|c|c|c|c|c|c|c|c|c|c|c|c|c|c|}
\hline \multirow{2}{*}{$\#$} & \multirow{2}{*}{ ITEM } & \multirow[b]{2}{*}{ 迹 } & \multicolumn{5}{|c|}{$\begin{array}{l}\text { 崫 } \\
\text { 岁 } \\
\text { क }\end{array}$} & \multicolumn{5}{|c|}{$\begin{array}{l}\text { 山्户 } \\
\text { 岁 } \\
\text { 올 }\end{array}$} & \multirow{2}{*}{$\begin{array}{l}\text { 唇 } \\
\text { ㅇ } \\
\\
\text { 匹 }\end{array}$} & \multicolumn{2}{|c|}{ 㱏 } & \multicolumn{2}{|c|}{ ౌ } \\
\hline & & & के & $\begin{array}{l}\text { क } \\
\text { कि }\end{array}$ & $\stackrel{\Xi}{\Sigma}$ & $\mathbb{H}$ & 总 &  & $\ddot{a}$ & யூ & $\underset{a}{a}$ & 山्山 & & 웅 & 㟔 & $\begin{array}{l}\text { 을 } \\
\text { 를 } \\
\frac{\alpha}{\alpha}\end{array}$ & ల్ల \\
\hline 1. & $\begin{array}{l}\text { Contrato de Gestão } \\
\text { (íntegra) }\end{array}$ & & DO & & & & & D0; I & & & & & & & & DO & \\
\hline & $\begin{array}{l}\text { Minuta do Contrato } \\
\text { de Gestão }\end{array}$ & & DO & & DO & & DO & J & DO; J; I & & & & DO & & & & \\
\hline 3. & Relatório de Execução & DO & DO & DO & $\mathrm{DO}^{1}$ & DO & & DO & DO; J; I & DO & DO & $P$ & DO & DO & DO & DO & \\
\hline 4. & Relatório Financeiro & DO & DO & DO & $\mathrm{DO}^{2}$ & DO & & DO & DO; J; I & DO & DO & DO; J & DO & DO & DO & DO & \\
\hline & $\begin{array}{l}\text { Relatório de } \\
\text { Desempenho }\end{array}$ & & DO & & & & & & $\mathrm{J} ; \mathrm{I}$ & & & $P$ & & & & & \\
\hline 6. & $\begin{array}{l}\text { Procedimento para } \\
\text { Contratação (obras, } \\
\text { compras etc.) }\end{array}$ & $P$ & DO & DO & $P$ & & $P$ & D0; I & $P$ & $P$ & $P$ & $P$ & & DO & $P$ & $P$ & \\
\hline 7. & Balanço & & DO & & & & & & J; I & & & & & & & & \\
\hline & $\begin{array}{l}\text { Demais Prestações } \\
\text { de Contas }\end{array}$ & & DO & & & & & & J; I & & & & & & & & \\
\hline 9. & $\begin{array}{l}\text { Nome do Dirigente } \\
\text { Responsável }\end{array}$ & & & & DO & & & & & & & & & & & & \\
\hline $\begin{array}{l}\mathrm{DO}- \\
\mathrm{I}-\mathrm{Int} \\
\mathrm{J}-\mathrm{Jor} \\
\mathrm{P}-\mathrm{Ob} \\
1 \text { e } 2\end{array}$ & $\begin{array}{l}\text { Diário Oficial } \\
\text { ernet } \\
\text { nal de grande circulação } \\
\text { rigatoriedade de publicaç } \\
\text { - Publicação do extrato } \\
\text { revê a apresentação de re }\end{array}$ & o ( & es & ifica & eio) & & due & & & & & & & & & & \\
\hline
\end{tabular}


que boa parte das OS nasceu ou como mero mimetismo institucional (POLLITT e BOUCKAERT, 2000) ou como uma forma simplória de burlar as normas da administração pública, visando mais à autonomia gerencial, sem garantir o controle sobre tais entidades. Contra o modelo da NGP, percebe-se uma flexibilização sem accountability. Por outro lado, os contratos de gestão, com exceção da Bioamazônia, foram localizados na Internet, indicativo de transparência de gestão.

A publicação do Relatório de Execução e do Relatório Financeiro é obrigatória na maioria dos casos. Em Santa Catarina, está prevista a apresentação de tais relatórios aos órgãos internos de controle. Apenas em Vitória não há menção explícita desses instrumentos de publicização e transparência.

A existência e a publicação desses relatórios não levam necessariamente à accountability, pois não trazem instrumentos que incentivem a participação dos cidadãos. Podese compensar isso pela atuação da sociedade no conselho de administração, cuja composição, para o caso federal, está definida na Lei $\mathrm{n}^{\circ}$ 9.637/98.

Há também preocupação em tornar públicos os procedimentos para a contratação de obras, serviços e compras, cujas regras devem ser elaboradas pela própria organização social, sem a necessidade de licitação. Tal publicação não é obrigatória em Santa Catarina, mas as regras devem ser aprovadas pelo Conselho de Administração da organização social, e a lisura seria garantida pela participação de membros do poder público e de representantes da sociedade civil. Apenas a legislação do Espírito Santo e do Pará não mencionam esse tipo de procedimento, revelando a possibilidade de disjunção entre flexibilização administrativa e accountability.

Em termos comparativos, São Paulo é o estado que especifica o maior número de documentos que devem ser publicizados. A preocupação com o controle manifestase também na criação de uma unidade específica dentro da Secretaria da Saúde para fazer o acompanhamento dos contratos de gestão. Os casos da Bahia e de Pernambuco também se diferenciam por explicitarem a publicação de diferentes documentos na Internet e em jornais de grande circulação. Esse é um requisito para dar validade ao contrato em Pernambuco, embora não tenhamos encontrado materiais relativos a uma das OS, qual seja, a Casa do Estudante.

A obrigatoriedade de publicação na Internet aponta para uma ampliação dos mecanismos de transparência e controle para além dos tradicionais, reforçando a importância do governo eletrônico como um uma forma nova de informar os cidadãos. Nesse caso, percebe-se bem como as inovações gerenciais, vinculadas à tecnologia de gestão, podem ser importantes para melhorar o desempenho das políticas e favorecer a maior responsabilização da administração pública.

\section{AS ORGANIZAÇ̃̃ES SOCIAIS DE SAÚDE EM SÃO PAULO: SUCESSOS E FRACASSOS DO MODELO INSTITUCIONAL}

Em São Paulo, a partir da Lei Complementar $n^{\circ} 846$, de 4 de junho de 1998, as organizações das áreas da Saúde que atendessem aos requisitos da lei poderiam pleitear qualificação como organizações sociais, assinando um contrato de gestão com o Estado. Entre as condições necessárias estão: atuar na área da Saúde ou da Cultura por mais de cinco anos, e ser pessoa jurídica de direito privado e sem fins lucrativos. A lei estadual, apesar de ter utilizado a legislação federal como modelo, apresenta algumas diferenças, entre elas o fato de ter sido mais restritiva quanto às áreas em que as entidades podem ser qualificadas.

Verificamos, ademais, no Quadro 4, a lista das OS de Saúde em São Paulo e a data da qualificação. Algumas OS são responsáveis pela administração de dois hospitais, e, nesses casos, a data na parte inferior do campo "Data de qualificação" indica o início das atividades do segundo hospital. Ao todo, nove entidades foram qualificadas e são responsáveis pela gestão de 13 hospitais, um ambulatório de especialidades, um centro de referência do idoso e um laboratório.

A adoção do modelo de contratos de gestão, por sua vez, foi expandida para cinco hospitais da administração direta, conforme apresenta o Quadro 5. Trata-se, segundo Levy (2004, p. 6), de uma "crescente capacidade da Secretaria da Saúde em supervisionar as OS, o que aliás lhe valeu o aprendizado que agora transfere para as unidades que operam no sistema tradicional da administração direta".

A elaboração do projeto de lei e sua aprovação no Legislativo apresentam nuances que nos remetem à década de 1980. De acordo com Tanaka e Melo (2002), no governo Montoro foi iniciada a construção de 10 hospitais no estado de São Paulo como parte de uma estratégia de regionalização do atendimento à saúde, contando com o financiamento do Banco Mundial. Ainda de acordo com esses autores, a localização dos hospitais e o perfil dos serviços foram definidos após ampla participação dos movimentos populares de saúde, com uma expectativa de se atingir uma população estimada, à época, em 200 mil habitantes. 
Mas a adoção do modelo das OS teve forte vinculação com o contexto financeiro vivido pelo governo Mário Covas. Como não poderia aumentar mais seus gastos com pessoal por conta da Lei de Responsabilidade Fiscal (LRF), o então governador optou por transformar os novos hospitais em OS, porque se o fizesse pela via da administração direta estaria batendo de frente com a nova ordem financeira estabelecida pela União. Cabe ressalvar que a forma como foi feita a opção por flexibilizar a gestão nesse caso da Saúde pode eventualmente gerar apenas uma válvula de escape para as contas públicas, quando a transformação do modelo de gestão deveria ser uma solução mais profunda e de longo prazo.

Antes da aprovação da lei das OS paulistas, houve uma audiência pública, realizada, no dia 15 de abril de 1998, na Assembléia Legislativa de São Paulo (Alesp), com a participação de deputados estaduais, prefeitos e vereadores de diversas cidades, representantes de diferentes setores da sociedade, como do Conselho Estadual de Saúde, de diferentes Conselhos Municipais de Saúde, do Conselho dos Secretários Municipais de Saúde, de movimentos po- pulares, das universidades, diretores de hospitais, entre outros.

No debate em relação ao Projeto de Lei Complementar $n^{0} 3 / 98$, os principais motivos contrários foram de quatro ordens: (a) a privatização da saúde; (b) a dificuldade de controle social, lembrando que o paradigma do SUS estrutura-se sob o princípio da participação dos usuários; (c) a lei ter desconsiderado o Código Estadual de Saúde, que fora aprovado no início do governo Covas; e (d) o poder discricionário do Executivo na qualificação de OS. Esta última preocupação, externada principalmente pela oposição na Assembléia, já revelava um possível obstáculo à melhor responsabilização das OS, que se confirmaria na prática.

Para a defesa, os argumentos basearam-se na proposta de que as OS dariam o atendimento universal da população por meio do SUS, na criação de mecanismos de controle social previstos em lei, na flexibilidade do novo modelo de gestão e no controle dos resultados por meio do contrato de gestão. Avaliaremos a seguir o quanto essas promessas se realizaram.

Quadro 4 - Organizações sociais de saúde qualificadas em São Paulo

$\#$ ORGANIZACẼO SOCIAL

Serviço Social da Indústria da Construção Civil e do Mobiliá-

1. rio de SP (Seconci)

2. Sociedade Paulista para o Desenvolvimento da Medicina (Unifesp)

3. Associação Congregação de Santa Catarina

4. Associação Beneficente Casa de Saúde Santa Marcelina

5. Irmandade da Santa Casa de Misericórdia de São Paulo

6. Sanatorinhos Ação Comunitária de Saúde

7. Organização Santamarense de Educação e Cultura (OSEC)

8. Fundação $A B C$

9. Sociedade Assistencial Bandeirantes

\section{DATA DE QUALIFICAÇÃO}

23.10.1998

21.10.1998

24.8.2000

26.6.1998

20.10 .1998

26.6.1998

16.12.1999

16.12.1999

20.10.1998

23.10.1998

2004

17.8.2001

\section{UNIDADE}

1. H Itapecerica da Serra

2. H. Vila Alpina

3. H. Pirajuçara

4. H. Diadema

5. H. Pedreira

6. H. Itapevi*

7. Centro Ref. Idoso

8. H. Itaim Paulista

9. H. Itaquaquecetuba

10. H. Guarulhos

11. Amb. Especialidades

12. H. Carapicuíba

13. H. Grajaú

14. H. Francisco Morato

15. H. Santo André

16. Centro Est. Análises Clínicas

* A gestão do Hospital Geral de Itapevi passou da Sanatorinhos Ação Comunitária de Saúde para a Associação Congregação de Santa Catarina em dezembro de 2005.

Fonte: Secretaria Estadual de Saúde. 


\section{0 desempenho das organizações sociais de Saúde: os primeiros (bons) resultados}

A implementação em São Paulo das OS na área de Saúde já foi objeto de estudos que procuraram analisar os resultados gerenciais desse modelo (FERREIRA JÚNIOR, 2003; WORLD BANK, 2006; COSTA e RIBEIRO, 2005).

Observando o período de 2000 a 2002, Ferreira Júnior (2003, p. 252) constatou nas OS uma capacidade de produzir mais serviços sem grande variação financeira, em comparação com hospitais públicos de administração direta. Segundo o autor, houve um incremento significativo das internações, atendimentos ambulatoriais e de urgência por parte dos hospitais administrados por meio de contrato de gestão. Segundo trabalho do Banco Mundial, as OS possuem menor índice de mortalidade. Costa e Ribeiro (2005) montaram um Índice de Eficiência Organizacional que revelou, no caso paulista, que nove entre os dez hospitais mais eficientes eram OS. Embora tivessem um orçamento um pouco maior do que os hospitais geridos pela administração direta (variação de $8,1 \%$ ), seu custo médio era significativamente menor (em torno de $25 \%$ ).

Avanços também foram obtidos na gestão de pessoal. A maior autonomia para contratação, promoção e demissão permite aos dirigentes das OS selecionar melhor os funcionários, segundo habilidades efetivamente requeridas pelos objetivos organizacionais. A flexibilidade derivada da contratação pela CLT, e não pelo Regime Jurídico Único, também possibilita demitir com maior facilidade aqueles que não cumprem os objetivos organizacionais. $\mathrm{Na}$ administração direta, só podem ser dispensados os que cometem falta muito grave, de modo que a permanência e mesmo a progressão no serviço público têm pouca relação com o desempenho de cada servidor

Por fim, é possível assinalar avanços no campo da transparência. Em comparação com os dados da própria administração direta, as OS apresentam mais informações sobre o desempenho gerencial e os resultados alcançados. O contrato de gestão e a sua publicização tornam mais claras as metas e as missões das OS de Saúde (OSS) se comparadas às administradas diretamente pelo pode público. Essa transparência possibilita, em tese, maior ativação da cidadania e dos controles. Porém, o sucesso da responsabilização depende muito de "como" e "se" as instituições de accountability acionarão seus instrumentos de controle e fiscalização. Eis o maior problema das OS paulistas.

\section{A accountability das organizações sociais de Saúde em São Paulo: 0 não-cumprimento das promessas da NGP}

Do ponto de vista da gestão e da responsabilização, o principal elo entre o Estado e a organização social é representado pelo contrato de gestão. Em São Paulo, ele é apresentado no artigo 6 da Lei Complementar n ${ }^{\circ}$ 846/98 como

... o instrumento firmado entre o Poder Público e a entidade qualificada como organização social, com vistas à formação de uma parceria entre as partes para fomento e execução de atividades relativas à área da saúde ou da cultura. (SÃO PAULO, 1998b)

Essa mesma lei expressa a preocupação com a accountability das atividades desenvolvidas pelas OS em dois momentos. A primeira referência ocorre logo na Seção I, que trata da qualificação das entidades e que, em seu parágrafo único, estabelece que as OS

... serão submetidas ao controle externo da Assembléia Legislativa, que o exercerá com o auxílio do Tribunal de Contas do Estado, ficando o controle interno a cargo do Poder Executivo. (Artigo $1^{\circ}$, parágrafo único, grifo nosso)

Quadro 5 - Instituições que mantêm convênio com a SES por meio de contrato de gestão

\begin{tabular}{|c|l|c|c|}
\hline$\#$ & \multicolumn{1}{|c|}{ ORGANIZAÇÃo SOCIAL } & DATA DE QUALIFICAÇÃO & HOSPITAL \\
\hline 1. & Hospital das Clínicas da Unicamp & 2000 & Sumaré \\
\hline 2. & Faculdade de Medicina de Botucatu (Unesp) & 2002 & Bauru \\
\hline 3. & Fundação Faculdade de Medicina da USP & 2003 & Sapopemba \\
\hline 4. & $\begin{array}{l}\text { Sociedade Paulista para o Desenvolvimento da Medicina } \\
\text { (Unifesp) }\end{array}$ & 2.2001 & H.C. Luíza de Pinho Mello \\
\hline 5. & Sociedade Assistencial Bandeirantes & & Vale do Paraíba \\
\hline
\end{tabular}

Fonte: Secretaria Estadual de Saúde. 
Quanto à fiscalização do contrato de gestão, a legislação estabelece que

\begin{abstract}
... a execução do contrato de gestão celebrado por organização social será fiscalizada pelo secretário de Estado da Saúde. [...] Os resultados atingidos com a execução do contrato de gestão serão analisados, periodicamente, por comissão de avaliação indicada pelo secretário de Estado competente, composta por profissionais de notória especialização, que emitirão relatório conclusivo, a ser encaminhado àquela autoridade e aos órgãos de controle interno e externo do Estado. (Artigo 9o, caput e $\S$ $2^{\circ}$, grifos nossos)
\end{abstract}

Essa Comissão de Avaliação, além dos membros indicados pelo secretário de Estado da Saúde, deve ser composta por dois integrantes indicados pelo Conselho Estadual de Saúde e dois membros integrantes da Comissão de Saúde e Higiene da Assembléia Legislativa (Artigo $9^{\circ}, \S 3$ ).

A presença de deputados e também de membros do Conselho Estadual de Saúde amplia as possibilidades de controle, parlamentar e social, uma vez que à Comissão de Saúde e Higiene "compete opinar sobre proposições e assuntos de defesa, assistência e educação sanitária, bem como de organização ou reorganização de repartições da administração direta ou indireta aplicadas a esses fins" (ALESP, 2002). Já a participação de integrantes do Conselho Estadual de Saúde amplia as possibilidades de controle social, uma vez que o Código de Saúde do Estado de São Paulo, de acordo com a Lei Complementar $n^{\circ} 791 / 95$, o define como "o órgão pelo qual se efetiva a participação da comunidade na gestão do SUS" e diz também que ele "exerce função de controle social das atividades governamentais na área".
A Resolução SS 142/01 e sua Retificação apresentam o modelo de contrato de gestão para as partes interessadas, estabelecendo ainda a responsabilização da "Coordenadoria de Contratação de Serviços de Saúde (CCSS)" da Secretaria de Estado da Saúde (SES) pelo acompanhamento da execução dos contratos. Com a Resolução SS 10/00, criou-se o "Grupo de Trabalho Especial", atuando junto ao Gabinete do Secretário de Estado da Saúde, para coordenar e articular as atividades relacionadas exclusivamente aos contratos de gestão.

Em seu artigo 11, a lei estadual das OS, quanto à possibilidade de controle social, afirma que

... qualquer cidadão, partido político, associação ou entidade sindical [é] parte legítima para denunciar irregularidades cometidas pelas organizações sociais ao Tribunal de Contas ou à Assembléia Legislativa. (Artigo 11, grifo nosso)

Em relação ao TCE, além de acatar as denúncias mencionadas, a legislação ainda estabelece que "o balanço e demais prestações de contas da organização social devem, necessariamente, ser [...] analisados pelo Tribunal de Contas do Estado de São Paulo" (Artigo 12, grifo nosso).

A partir da definição expressa na lei, a relação entre o tipo de responsabilização e seu controlador está representada no Quadro 6.

O estado de São Paulo é, dentro da Federação brasileira, o que mais se aproxima das preocupações da NGP. Com base em um estudo mais detalhado dos diversos mecanismos previstos, a seção seguinte procurará analisar se este modelo se efetivou na prática.

\section{Quadro 6 - Órgãos fiscalizadores e o tipo de responsabilização das OS da Saúde}

\begin{tabular}{|c|c|c|c|c|c|}
\hline \multirow{2}{*}{$\#$} & \multirow{2}{*}{ CONTROLADOR } & \multicolumn{4}{|c|}{ TIPO DE RESPONSABILIZAÇÃO } \\
\hline & & PARLAMENTAR & PROCEDIMENTOS & RESULTADOS & SOCIAL \\
\hline 1. & Comissão de Avaliação & & & $x$ & \\
\hline 2. & $\begin{array}{l}\text { Coordenadoria de Contratação de Serviços } \\
\text { de Saúde }\end{array}$ & & $x$ & $\mathrm{X}$ & \\
\hline 3. & Grupo de Trabalho Especial & & $x$ & $x$ & \\
\hline 4. & Assembléia Legislativa & $x$ & & & \\
\hline 5. & Tribunal de Contas do Estado & & $x$ & & \\
\hline 6. & Usuários & & & & $X$ \\
\hline
\end{tabular}




\section{CONTROLE DE RESULTADOS}

O controle de resultados é o principal mecanismo de responsabilização presente no contrato de gestão, pois neste constam, em detalhe, as metas que devem ser atingidas pelos hospitais, individualmente, geridos por uma organização social. A Comissão de Avaliação realiza uma análise das atividades desenvolvidas pelas OS. Essa análise deve recair exclusivamente sobre os resultados atingidos. A Coordenadoria de Contratação de Serviços de Saúde, subordinada à Secretaria de Estado da Saúde, é a responsável pelo acompanhamento rotineiro da execução do contrato e deve elaborar seus próprios relatórios de atividades.

Para auxiliar os responsáveis pelo controle, a legislação estabelece a elaboração dos documentos relacionados no Quadro 7.

A Organização Social deve, mensalmente, enviar relatórios à Secretaria de Estado da Saúde com dados relativos à produção assistencial, indicadores de qualidade e movimentação de recursos econômicos e financeiros.

O Relatório de Execução é um documento específico sobre a realização do contrato de gestão, mostrando resultados alcançados pela organização social. Esse documento deve ser preparado pela OS e apresentado ao final de cada exercício "ou a qualquer momento, conforme recomende o interesse público" (SÃO PAULO, 1998b). Esse documento e sua respectiva prestação de contas devem ser analisados pelo Tribunal de Contas do Estado e publicados no DOE de São Paulo.

A Comissão de Avaliação é a responsável pela elaboração de dois relatórios: de Atividades e de Desempenho. O primeiro discrimina as atividades realizadas pela organização social. O relatório de desempenho é anual e deve conter um parecer conclusivo sobre as atividades da OS e, junto com o de Execução, ser encaminhado ao secretário de Estado da Saúde. Com base na análise de ambos os documentos, o governador toma uma decisão quanto à manutenção da qualificação da entidade como OS. Além dos relatórios, o controle de recursos financeiros também é adotado como uma forma de acompanhar a execução do contrato e penalizar eventuais descumprimentos de metas.

\section{0 controle de recursos financeiros}

O controle dos recursos financeiros está condicionado, como mencionado, às análises periódicas de desempenho realizadas pela Comissão de Avaliação. Assim, são definidos os percentuais de repasse, as necessidades de aditivos contratuais ou de redução de metas, e, inclusive, pode-se chegar ao extremo de se desqualificar o hospital como uma OS de saúde.

Do orçamento estipulado em contrato, o repasse para as OS ocorre de duas formas: (1) do valor total, $90 \%$ são repassados às OS de saúde em parcelas mensais de valor fixo; e (2) o repasse dos 10\% restantes depende da consecução das metas contratuais.

Além desse mecanismo, o valor total previsto em contrato pode alterar-se de acordo com as metas atingidas pela organização, com duas avaliações semestrais (julho e dezembro). Quando a OS não atinge patamares mínimos de performance ( $85 \%$ do volume de atividades contratado), existe uma redução no valor do orçamento do hospital.

A diretora administrativa do Hospital Santa Marcelina, Vivian Hart Ferreira, em entrevista realizada em 16 de janeiro de 2003, considera que o critério de divisão do orçamento em parte fixa e parte variável "é um grande incentivo à melhoria", e o recurso que "vem em função disso [metas alcançadas] não é um presente, é uma conquista". Para Maria Alice Ferreira, diretora administrativa dos hospitais de Pirajuçara e Diadema, entrevistada em

Quadro 7 - Instrumentos para controle das OS

\begin{tabular}{|c|l|c|c|}
\hline$\#$ & \multicolumn{1}{|c|}{ INSTRUMENTOS PARA CONTROLE } & RESPONSÁVEL PELA ELABORAÇÃO & PERIODICIDADE \\
\hline 1. & Documentos das Atividades & OS & Mensal \\
\hline 2. & Relatório de Execução & Anual \\
\hline 3. & Relatório Financeiro & OS & Anual \\
\hline 4. & Relatório das Atividades & Comissão de Avaliação & Trimestral \\
\hline 5. & Relatório de Desempenho & Comissão de Avaliação & Anual \\
\hline 6. & Relatório de Atividades & CCSS & Variada \\
\hline
\end{tabular}


26 agosto de 2002, "esses $10 \%$ são fundamentais para o hospital, principalmente porque se parte da premissa de que o recurso destinado atende às suas necessidades de orçamento. [E a] forma de pagamento é interessante, pois premia aqueles que atingiram as metas estipuladas. Acho que é um incentivo para buscar quantidade com qualidade".

\section{O controle parlamentar e de procedimentos}

Dos quatro tipos de controle parlamentar apresentados anteriormente, no caso das OS paulistas, há as seguintes dinâmicas de controle: audiências públicas, comissões parlamentares e o controle das contas enviadas pelo Executivo.

A audiência pública sobre a criação de OS em São Paulo ocorreu na Assembléia Legislativa, no dia 15 de abril de 1998, com presença ativa de vários setores da sociedade. Existe ainda a "Comissão de Saúde e Higiene", previamente citada. Para o controle das contas do Executivo, existe a Comissão de Fiscalização e Controle, que deve "fiscalizar os atos da administração direta e indireta do Estado" (ALESP, 2002).

O Tribunal de Contas do Estado (TCE), ao auditar a documentação enviada pela Secretaria de Estado da Saúde, auxilia a Assembléia Legislativa no controle das OS. Além disso, o TCE passou a realizar, conforme indicam as entrevistas, visitas aos hospitais, realizando auditorias nos procedimentos administrativos. Para Fábio Tadeo Teixeira, diretor administrativo do Hospital Geral de Pedreira, entrevistado em 15 de outubro de 2002, "as primeiras visitas foram mais de reconhecimento da atividade do que de fiscalização. Hoje, eles já fiscalizam com outros olhos, são mais pontuais, pedem documentos específicos, eles evoluíram".

O TCE tem relatado problemas de prestação de contas das OS paulistas. Numa análise sobre o Hospital Geral de Itaquaquecetuba, o TCE manifestou-se sobre a ausência do relatório a cargo da Secretaria da Saúde, quase sete anos após a assinatura do contrato de gestão, sinalizando uma falta grave do Poder Executivo em termos de accountability. Mesmo assim, não tem havido punições maiores; somente sugestão de correções de conduta e solicitação de novas informações. Em outras palavras, o Tribunal de Contas, não obstante não receba sempre todos os necessários para a efetiva responsabilização das organizações sociais, não é capaz de mudar o controle quase exclusivo que o governo estadual exerce sobre os contratos.

Poucos entrevistados notaram a atuação da Assembléia, por meio da Comissão de Saúde e Higiene, como controladora, a não ser uma entrevistada, que disse ter recebi- do a "visita da Comissão de Saúde, mais de uma vez". Na análise de Fábio Tadeo Teixeira, dirigente do Hospital de Pedreira,

... nós nunca percebemos que éramos fiscalizados pela Assembléia Legislativa. O que a gente sente [...] é quando a Secretaria [de Estado da Saúde] nos pede algumas informações e diz que é para enviar aos deputados. Nós fomos convidados a participar de duas reuniões, mas não como uma fiscalização. (grifo nosso)

A avaliação mais contundente é a de Walter Cintra Ferreira, ex-gerente do Hospital Geral de Itapecerica da Serra, entrevistado em 11 de abril de 2002, para quem a Assembléia Legislativa tem "uma participação bastante descomprometida". Uma das causas pode estar na redução das reuniões da Comissão de Avaliação. Como as OS da Saúde são uma iniciativa da gestão Mário Covas (PSDB), e como desde então o governo estadual se manteve sob comando tucano, o interesse maior na fiscalização dos hospitais seria da oposição.

O ex-deputado Carlos Neder, que participou da Comissão de Avaliação como representante da Assembléia, afirmou: "Posso assegurar que, no âmbito estadual, os instrumentos de controle público sobre as OS da Saúde são muito débeis e que o acesso às informações gerenciais $\mathrm{e}$ financeiras é precário". Uma de suas iniciativas para ampliar a transparência na gestão dessas OS foi a inclusão de um artigo na Lei de Diretrizes Orçamentária (Lei $\mathrm{n}^{\circ}$ 11.971/05, art. 35) para o ano de 2006, obrigando a publicação periódica dos resultados.

A Assembléia propôs outra medida de "controle": a criação de uma data específica para comemorar "o Dia das Organizações Sociais da Saúde". Pela Lei $n^{\circ}$ 11.622, de 7 de janeiro de 2004, essa reunião acontece anualmente em 4 de junho. Neste fórum, a composição dos membros vinculados ao governo estadual evita aprofundar a fiscalização e a crítica das OS, limitando avanços na accountability.

Observando a legislação referente às OS, a fragilidade do controle parlamentar não parece ter uma relação direta com o modelo institucional adotado. Houve avanços importantes em termos de mecanismos de fiscalização, criando instrumentos que muitas vezes não há nem para o controle da administração direta. Entretanto, a baixa participação da Assembléia Legislativa no processo de responsabilização é impressionantemente notada tanto pelos deputados como controladores quanto pelos dirigentes das Organizações Sociais como controlados, evidência muito forte da ineficácia da accountability nesse aspecto. Aqui, 
a análise da percepção dos atores foi fundamental para evitar uma visão institucional formalista.

Mas essa situação de inoperância do controle parlamentar, como dito acima, tem pouco a ver com o desenho institucional das OS paulistas. A raiz desse problema está, num plano mais geral, no insulamento e concentração de poderes no Executivo em relação aos controles horizontal e social, fenômeno histórico observado por uma extensa literatura (ver, por exemplo, NUNES, 1997; e FIGUEIREDO, 2002). Apesar de ter havido democratização das arenas decisórias desde a redemocratização, ainda há no Brasil predomínio desmedido do Executivo em relação aos demais pólos de poder, algo que ocorre nos momentos de montagem da agenda pública, escolha de alternativas, formulação, implementação e avaliação/ fiscalização das ações governamentais.

Na grande maioria dos estados, há predominância de um padrão ultrapresidencialista, no qual há forte dominância do Executivo sobre os demais poderes (ABRUCIO, 1998; PEREIRA, 2004; CLEMENTE, 2007). Isso tem se repetido em outras questões, como no caso das agências reguladoras, cuja governança é igualmente marcada pela concentração de poderes nas mãos das governadorias (PÓ e ABRUCIO, 2007).

Cabe ressaltar que a participação dos deputados estaduais paulistas foi muito maior no momento de criação da legislação sobre as organizações sociais do que na implementação da política e na fiscalização de tais entidades, o que marca a dificuldade de se estabelecer uma responsabilização parlamentar ininterrupta. Isso confirma resultados de pesquisas recentes, que revelam maior participação das Assembléias no processo de deliberação das políticas do que no controle do Executivo (CLEMENTE, 2007).

\section{0 controle social}

O esperado controle social descrito no Plano Diretor, elaborado por Bresser-Pereira, encontra pouco espaço nas OS paulistas. A participação da sociedade, por meio do Conselho de Administração das OS ou dos representantes do Conselho Estadual da Saúde, na definição das metas e indicadores para cada OS, ainda não é uma realidade.

Segundo dirigentes de hospitais entrevistados, os objetivos de cada organização social são definidos pela Secretaria de Estado da Saúde após estudo epidemiológico da região onde cada hospital está localizado e apresentados às OS e a seus conselhos de administração, que pouco podem fazer para alterar o quadro.

O Conselho Estadual de Saúde (CES), composto por representantes de diferentes setores (público, privado, usuários e trabalhadores) e presidido pelo secretário es- tadual de Saúde, é uma das principais instâncias responsáveis pelo controle social das ações na área. Essa atividade inclui também o acompanhamento e a avaliação das OS de saúde.

O acompanhamento da atuação desse Conselho foi feito mediante a análise das Atas de Reunião disponibilizadas na Internet, que abrangem da $102^{\mathrm{a}}$ reunião de 11/03/2003 até a $148^{a}$ reunião de 18/05/2007. O tema é discutido principalmente na Comissão de Políticas (CP) e na Comissão de Orçamento, Finanças e Prestação de Contas.

Percebe-se pelas atas a ocorrência de dois tipos de debates: um é permeado por um embate ideológico, em que se discute a natureza do modelo das OS dentro dos princípios do SUS; o outro envolve questões objetivas como a participação do Conselho Estadual de Saúde no acompanhamento e na avaliação das OS.

O Conselho Estadual de Saúde já se manifestou contrariamente às OS, mas isso não teve impacto efetivo sobre a política pública, pois o Executivo não levou isso em consideração. $\mathrm{O}$ espaço em que o controle social poderia ser mais efetivo é o da Comissão de Avaliação, porém é exatamente aqui que a manifestação dos membros de fora do estado tem ocorrido com menor intensidade e importância.

Percebe-se um afrouxamento dos mecanismos originais de controle social, como já ocorrera no caso da accountability parlamentar. As arenas institucionais existentes como no caso da Comissão de Avaliação - têm sido subaproveitadas. O fato é que, embora o desenho institucional das OS paulistas possibilite formas de controle, elas têm sido pouco ativadas, porque, na prática, predomina uma hipertrofia do Executivo.

O estudo das OS de saúde em São Paulo mostra que as idéias da NGP no Brasil têm maior ligação com o legado e o contexto administrativo brasileiro (em particular, o da esfera estadual) do que com o próprio desenho institucional proposto - até porque o modelo paulista é bem melhor do que o dos outros estados, inclusive no que se refere à responsabilização governamental, conforme se observou no Quadro 4, anteriormente.

É bem verdade que as regras de funcionamento das OS em São Paulo trouxeram ganhos em termos de gestão e de transparência, mas o seu limite pode ser visto na capacidade de ativar os instrumentos de accountability, muito mais determinados pelas restrições do insulamento estatal e da hipertrofia histórica do Poder Executivo, e de modo mais específico pelo ultrapresidencialismo estadual. Tal conclusão alinha-se com a literatura comparada das reformas, particularmente os trabalhos de Pollitt e Bouckaert (2000, 2002), os quais, ao criticarem a visão 
do mimetismo institucional, mostram o papel decisivo do sistema político-administrativo nos resultados efetivos das reformas.

\section{CONCLUSÃO}

O modelo das OS no Brasil tem na experiência paulista o seu caso mais bem-sucedido. Em parte, isso se relaciona à precariedade do modelo ou de sua implementação nos outros estados e na União. No caso do governo federal, as OS são menos importantes, porque não foram disseminadas para mais áreas, principalmente as mais estratégicas, como nos setores da Educação e da Saúde. Nesse sentido, a reforma Bresser não logrou alterar o desenho institucional da administração pública no plano federal, permanecendo distante dos paradigmas que se instalaram recentemente em várias reformas pelo mundo.

Os avanços de gestão das OS da Saúde em São Paulo são evidenciados por dados referentes à eficácia e eficiência dos gastos públicos e à área de recursos humanos, ainda mais quando comparados ao desempenho dos hospitais estatais paulistas. A explicação desse sucesso das OS tem a ver, basicamente, com três fatores. Primeiro, com a flexibilização administrativa, que favorece um melhor gerenciamento. Segundo, com o mecanismo do contrato de gestão, que aumenta a capacidade de planejar e executar por meio de metas capazes de serem avaliadas. Por fim, com o êxito do modelo de repasse a entes públicos não estatais, que só deu certo em São Paulo, porque foi constituído um núcleo burocrático estratégico na Secretaria de Estado da Saúde, capaz de regular, monitorar, avaliar e, eventualmente, alterar o rumo do processo de contratualização. Ressalte-se que esses três aspectos também aparecem nas experiências bem-sucedidas de outros países no campo da gestão por resultados.

O sucesso gerencial obtido nas OS paulistas deixa mais claros os problemas do modelo administrativo público brasileiro. O governo de São Paulo, aliás, implementou posteriormente o contrato de gestão para algumas unidades da administração direta. O ideário da NGP hoje é compartilhado inclusive por parte daqueles que foram contrários à implantação das OS, tanto na União como nos estados, como no caso da proposta do ministro da Saúde, José Gomes Temporão (2007), de substituir o modelo atual de gestão dos hospitais pela chamada fundação estatal.

Entretanto, os instrumentos de accountability foram pouco utilizados no controle das OS paulistas. A hiper- trofia do Executivo vigente no Brasil, presente na forma de ultrapresidencialismo, é um grande obstáculo para reformas democratizadoras da administração pública. As entrevistas revelam que as instituições de controle têm sido pouco efetivas na responsabilização das OS de saúde em São Paulo. Por outro lado, constatou-se que a implantação desse modelo objetivou mais o problema fiscal do que as premissas da NGP. Mesmo sendo mais permeável ao controle do que o restante das experiências estaduais, o governo paulista, quando acionado por formas de cobrança e fiscalização, respondeu inadequadamente aos controladores.

A pergunta que fica ao final é a seguinte: qual seria a importância da accountability para a melhoria da gestão pública? De forma muito resumida, o que a literatura ressalta é que o aumento do controle sobre o poder público tem dois efeitos importantes. Primeiro, a responsabilização reduz as chances de erros dos governantes, pois ela pode corrigir tais equívocos ou, em última análise, levar à punição dos responsáveis. Trata-se aqui de um aperfeiçoamento cívico contínuo da sociedade como um todo. Mas a existência de múltiplos e ininterruptos instrumentos de accountability traz também a possibilidade de aprendizado por parte dos policymakers, sejam os políticos, sejam os burocratas. O paradigma da learning organization, um dos principais postulados de autores que têm refletido sobre a Nova Gestão Pública, só pode ser obtido reduzindo a concentração de poder e tornando-o mais accountable, para que sejam acesos alarmes de incêndio aos dirigentes públicos. Desse modo, a hipertrofia do Executivo e o ultrapresidencialismo no plano estadual, como evidenciados nos casos das OS paulistas na área da Saúde, constituem enormes obstáculos à efetiva modernização do Estado brasileiro.

\section{REFERÊNCIAS}

ABRUCIO, F. L. Os barões da federação: os governadores e a redemocratização brasileira. São Paulo: Hucitec, 1998.

ABRUCIO, F. L. Trajetória recente da gestão pública brasileira: um balanço crítico e a renovação da agenda de reformas. Revista de Administração Pública, Rio de Janeiro, edição comemorativa, v. 1, p. 67-74, 2007.

ABRUCIO, F. L.; FERREIRA COSTA, V. M. Reforma do Estado e o contexto federativo brasileiro. São Paulo: Konrad-Adenauer-Stiftung, 1998 (Pesquisas, $n^{\circ} 12$ ).

ABRUCIO, F. L.; GAETANI, F. Avanços e perspectivas da gestão pública nos estados: agenda, aprendizado e coalizão. Brasília: Consad, 2006. 
ALESP. Assembléia Legislativa do Estado de São Paulo. Descrição das atividades da Comissão de Saúde e Higiene da Assembléia Legislativa de São Paulo. Disponível em http://www.al.sp.gov.br/index4.htm. Acesso em 01.10.2002.

ALESP. Ata da 195ª Reunião Ordinária de 22 de dezembro de 2005. Disponível em http://www.al.sp.gov.br/StaticFile/integra_sessao/ 195aSO051222.htm. Acesso em 31.07.2007.

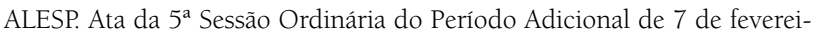
ro de 2007. Disponível em http://www.al.sp.gov.br/StaticFile/ integra_ sessao/005aSOPA070207.htm. Acesso em 31.07.2007.

ANDRÉ, M. A. de. Subsídios para a reforma do Estado: contratos de gestão. Brasília: IPEA/ENAP/IBAM, 1994, v. 4.

ANDRÉ, M. A. de. Contratos de gestão: contradições e caminhos da administração pública. RAE - revista de administração de empresas, São Paulo, v. 35, n. 3, p. 6-13, mai./jun. 1995.

ANDRÉ, M. A. de. A efetividade dos contratos de gestão na reforma do Estado. RAE - revista de administração de empresas, São Paulo, v. 39, n. 3, p. 42-52, jul./set. 1999.

BEHN, R. D. O novo paradigma da gestão pública e a busca da accountability democrática. Revista do Serviço Público, São Paulo, ano 49, n. 10, p. 5-44, out./dez. 1998.

BRADACH, J.; ECCLES, R. Price, authority and trust: from ideal types to plural forms. Annual Review of Sociology, UK, 15, 1989.

BRASIL. Lei nº 9.637, de 15 de maio de 1998. Dispõe sobre a qualificação de entidades como organizações sociais, a criação do Programa Nacional de Publicização, a extinção dos órgãos e entidades que menciona e a absorção de suas atividades por organizações sociais, e dá outras providências. Disponível em http://www.planalto.gov.br/ccivil_03/LEIS/L9637.htm. Acesso em 17.10.2002.

BRASIL. Presidência da República. Plano Diretor da Reforma do Aparelho do Estado. Brasília, 1995.

BRASIL. Ministério da Administração Federal e Reforma do Estado. Organizações Sociais. Brasília: Cadernos Mare, 1997.

BRASIL. Medida Provisória no ${ }^{\circ}$ 1.648-7, de 23 de abril de 1998. Convertida na Lei $n^{\circ} 9.637$, de 1998. Dispõe sobre a qualificação de entidades como organizações sociais, a criação do Programa Nacional de Publicização, a extinção do Laboratório Nacional de Luz Síncrotron e da Fundação Roquette Pinto e a absorção de suas atividades por organizações sociais, e dá outras providências. Disponível em http://www.planalto.gov.br/ccivil_03/MPV/ Antigas/1648-7.htm. Acesso em 17.11.2002.

BRASIL. Tribunal de Contas da União. Dirigentes de associação de comunicação deixam de prestar contas de recursos repassados e são multados. Notas de Imprensa, 10 maio 2001. Disponível em http://www. tcu.gov.br/imprensa/Notas/2001/maio/Roquette-Pinto.html. Acesso em 06.02.2003.

BRESSER-PEREIRA, L. C. Reforma do Estado para a cidadania: a reforma gerencial brasileira na perspectiva internacional. São Paulo: Editora 34, 1998.
CAMPOS, A. M. Accountability: quando poderemos traduzi-la para o português? Revista de Administração Pública, Rio de Janeiro, v. 24, n. 2, p. 30-50, fev./abr. 1990

CARNEIRO JÚNIOR, N.; ELIAS, P. E. A reforma do Estado no Brasil: as organizações sociais de saúde. Revista de Administração Pública, Rio de Janeiro, v. 37, n. 2, p. 201-226, mar./abr. 2003.

CES. Ata da $105^{a}$ Reunião do Conselho Estadual de Saúde de São Paulo, realizada em 27 maio 2003. Disponível em http://www.saude.sp.gov.br/ orgaos_colegiados/conselho_estadual/html/funcionamento/ ces_atal05. html. Acesso em 30.07.2007.

CES. Ata da $121^{a}$ Reunião do Conselho Estadual de Saúde de São Paulo, realizada em 19 nov. 2004. Disponível em http://sistema.saude.sp.gov.br/ gpad/reuniao.php?id=112\&iid=2. Acesso em 30.07. 2007.

CES. Ata da $143^{\mathrm{a}}$ Reunião do Conselho Estadual de Saúde de São Paulo, realizada em 24 nov. 2006. Disponível em http://sistema.saude.sp.gov.br/ gpad/reuniao.php?id=112\&iid=2. Acesso em 30.07.2007.

CNS. Deliberação n. 1, de 10 de março de 2005, do Conselho Nacional de Saúde. Disponível em http://conselho.saude.gov.br/deliberacoes/doc/2005/ deliberacao001.doc. Acesso em 30.07.2007.

CLAD. La responsabilización en la nueva gestión pública latinoamericana Buenos Aires: Eudeba, 2000

CLEMENTE, R. Variações de presidencialismos na federação brasileira: processo político e reforma nos estados, 1995-2006. Tese (Doutorado em Administração Pública e Governo) - Escola de Administração de Empresas de São Paulo, Fundação Getulio Vargas, São Paulo, 2007.

CUNILL GRAU, N. Responsabilización por el control social. In: CLAD La responsabilización en la nueva gestión pública latinoamericana. Buenos Aires: Eudeba, 2000

COSTA, N; RIBEIRO, J. M. Estudo dos modelos das organizações em hospitais públicos. Rio de Janeiro: Relatório. 2005

FARAH, M. F. S. Gestão pública e cidadania: iniciativas inovadoras na administração subnacional no Brasil. Revista de Administração Pública, Rio de Janeiro, v. 31, n. 4, p. 126-156, 1997.

FERREIRA JÚNIOR, V. C. Gerenciamento de hospitais estaduais paulistas por meio das organizações sociais de saúde. Revista de Administração Pública, Rio de Janeiro, v. 37, n. 2, p. 243-264, mar./abr. 2003.

FLYNN, N.; STREHL, F. Public Sector Management in Europe. London: Prentice Hall/Harvester. 1996

GALVÃO, M. C. C. P. (Coord) Novas formas de gestão dos serviços públicos: a relação público-privada. São Paulo: Fundap, 1997.

GROISMAN, E.; LERNER, E. Responsabilización por los controles clásicos In: CLAD. La responsabilización en la nueva gestión pública latinoamericana. Buenos Aires: Eudeba, 2000

KETL, D. Sharing Power: Public Governance and Private Markets Washington: Brooking Institution, 1993. 
LEVY, E. Organizações sociais no estado de São Paulo: estratégias de implementação e resultados. IX Congreso Internacional del CLAD sobre la Reforma del Estado y de la Administración Pública, Madrid, 2004. Disponível em: http://www.clad.org.ve/fulltext/0049827.pdf. Acesso em 30.09.2007.

MARTINS, H. F. Reforma do Estado na era FHC: diversidade ou fragmentação da agenda de políticas de gestão pública? São Paulo, 2002. Mimeografado.

NEDER, C. Carta às delegadas e aos delegados à $13^{\text {a }}$ Conferência Municipal de Saúde de São Paulo. 2005. Disponível em http://www.carlosneder.org. br/CN02/noticias/nots_det.asp?id=86. Acesso em 30.7.2007.

O'DONNELL, G. Accountability horizontal e novas poliarquias. Lua Nova, São Paulo, n. 44, p. 27-54, 1998.

PEREIRA, A. Por baixo dos panos: governadores e Assembléias no Brasil contemporâneo. Tese de Doutorado. Rio de Janeiro: Iuperj, 2004.

PÓ, M. V.; ABRUCIO, F. L. Desenho e funcionamento dos mecanismos de controle e accountability das agências reguladoras brasileiras: semelhanças e diferenças. Revista de Administração Pública, Rio de Janeiro, v. 40, n. 4, p. 679-698, jul./ago. 2006.

PÓ, M. V.; ABRUCIO, F. L. Mimetismo e reforma incompleta do Estado: o caso das agências reguladoras sob a égide do ultrapresidencialismo estadual. Paper apresentado na XXXI Enanpad. Rio de Janeiro, 2007.

POLLITT, C; BOUCKAERT, G. Public Management Reform: A Comparative Analysis. Oxford, UK: Oxford University Press. 2000

POLLITT, C; BOUCKAERT, G. Avaliando reformas da gestão pública: uma perspectiva internacional. Revista do Serviço Público, Brasília, v. 53, n. 3 , p. 5-29, jul./set. 2002
REZENDE, F. C. Por que falham as reformas administrativas? Rio de Janeiro: Fundação Getulio Vargas, 2004.

ROBLES, L. T; FISCHMANN, A. A. Contratos de gestão no estado de São Paulo: o caso das empresas estatais não-financeiras. RAE - revista de administração de empresas, São Paulo, v. 35, n. 4, p. 52-64, jul./ago. 1995.

SÃO PAULO (Estado). Lei Complementar no 791, de 9 de março de 1995. Estabelece o Código de Saúde no Estado.

SÃO PAULO (Estado). Lei Complementar no 846, de 4 de junho de 1998 Dispõe sobre a qualificação de entidades como organizações sociais e dá outras providências. Diário Oficial do Estado de São Paulo, v. 108, n. 106 , 1998b.

SÃO PAULO (Estado). Decreto n ${ }^{\circ}$ 43.493, de 29 de setembro de 1998 Dispõe sobre a qualificação das organizações sociais da área da cultura $e$ dá providências correlatas. Publicado no Diário Oficial do Estado de São Paulo, v. 108, n. 186, 30.09.1998. Disponível em http://www.imprensaoficial.com.br. Acesso em 11.02.2003.

TEMPORÃO, J. G. A fundação estatal fortalecerá o SUS. Folha de S. Paulo, 12.08.2007, p. A-3.

TCE. (2006). Ata da 32 $2^{a}$ Sessão Ordinária da Segunda Câmara, realizada em 21 de novembro de 2006. Disponível em http://www.tce.sp.gov.br/sessoes/ atas/segunda/2006_11_21_segunda_32so.pdf. Acesso em 30.07.2007.

TANAKA, O. Y.; MELO, C. (Org) Inovação e gestão: a organização social no setor saúde. São Paulo: Fapesp, 2002.

WORLD BANK. Brazil: Enhancing Performance in Brazil's health sector Lessons from Innovations in the State of São Paulo and the City of Curitiba. World Bank, 2006. Mimeo. 